\title{
Die leksikografiese bewerking van verwantskapsterme in Sepedi
}

\author{
D.J. Prinsloo, Departement Afrikatale, Universiteit van Pretoria, \\ Pretoria, Suid-Afrika (danie.prinsloo@up.ac.za)
}

Opsomming: Die verwantskapsterminologie van Sepedi is omvangryk en vorm 'n komplekse sisteem. In teenstelling met tale soos Afrikaans, Engels en Duits word groter uitdagings aan die Sepedileksikograaf gestel ten opsigte van die identifisering van verwantskapsterme en die lemmatisering en bewerking daarvan. Voorafstudie van die verwantskapsterminologiestelsel is ' $\mathrm{n}$ voorvereiste vir suksesvolle gebruikersleiding. Die Sepedi leksikograaf is die tussenganger tussen veral die onervare woordeboekgebruiker en hierdie ingewikkelde verwantskapsterminologiesisteem, en moet derhalwe sorg vir effektiewe lemmatisering en voldoende bewerking van verwantskapsterme. Die aard en omvang van verwantskapsterminologie in Sepedi word ontleed en daar word aangetoon dat verwantskapsterminologie in Sepedi problematies is, veral ten opsigte van die lemmatisering van samestellings, en in besonder, afgeleide enkelwoordvorme en frases, soos byvoorbeeld veelvuldige besitskonstruksies. Ten einde toegang tot verwantskapsterme in die woordeboek te vergemaklik word 'n leksikografiese konvensie vir die lemmatisering van verwantskapsterme voorgehou. Korpusvoorkomste van verwantskapsterme word aangegee en ruimte word afgestaan vir ' $n$ kritiese evaluering van die lemmatisering en bewerking van verwantskapsterme in Sepediwoordeboeke.

Sleutelwoorde: VERWANTSKAPSTERME, SEPEDI, STAMBOOM, PATERNE, LEMMATISERING, WOORDEBOEKKONVENSIE, LEKSIKOGRAFIESE BEWERKING, RESEPTIEWE WOORDEBOEKGEBRUIK, PRODUKTIEWE WOORDEBOEKGEBRUIK, GEBRUIKSFREKWENSIE

\begin{abstract}
The lexicographical treatment of kinship terminology in Sepedi. Kinship terminology in Sepedi is extensive and forms a complex system. In contrast to languages such as Afrikaans, English and German the lexicographer faces greater challenges in respect of the identification of kinship terms and the lemmatisation and treatment thereof in Sepedi dictionaries. Preparational studies of the kinship terminology system are a prerequisite for successful user guidance. The Sepedi lexicographer is the mediator, especially between the inexperienced dictionary user and this complicated kinship terminology system, and therefore has to provide for effective lemmatisation and sufficient treatment of kinship terms. The nature and extent of kinship terminology in Sepedi are analysed and it is indicated that kinship terminology in Sepedi is problematic, especially in respect of the lemmatisation of compounds, and in particular, derived single-word forms and phrases, such as for example multiple possessive constructions. In order to ease access to kinship terms in dictionaries, a lexicographic convention for the lemmatisation of kinship terms is suggested. Corpus occurrences of kinship terms are indicated and space is allocated for a critical evaluation of the lemmatisation and treatment of kinship terms in Sepedi dictionaries.
\end{abstract}


Keywords: KINSHIP TERMS, SEPEDI, FAMILY TREE, PATERNAL, LEMMATISATION, DICTIONARY CONVENTION, LEXICOGRAPHIC TREATMENT, RECEPTIVE DICTIONARY USE, PRODUCTIVE DICTIONARY USE, FREQUENCY OF USE

\section{Inleiding}

Die verwantskapsterminologie van Sepedi is omvangryk en vorm 'n komplekse sisteem. Prinsloo en Van Wyk (1992) poog om 'n paterne boomstruktuur te beskryf in terme van verskillende generasies, manlike en vroulike verwante, in terme van hoe 'n man (Ego) en sy vrou alle familielede van die man sal aanspreek of na hulle verwys.

Verwantskapsterme kom as enkelwoorde, samestellings en in konstruksies (hoofsaaklik besitskonstruksies) voor en die leksikograaf se dilemma is om lemmatiseringstrategieë te identifiseer wat alle verwantskapsterme in Sepedi in 'n omvattende woordeboek sal ondervang. Bestaande woordeboeke bied bloot selektief lemmas aan wat op grond van gebruiksfrekwensie in 'n korpus, of intuïtief geselekteer is. In hierdie artikel word 'n meer uitgebreide sisteem soos deur Prinsloo en Van Wyk (1992) voorgehou word as vertrekpunt geneem vir die voorgestelde lemmatiseringsproses. Hierdie sisteem, hoewel omvattend, bied ten beste net die terme vir familielede van die man. Die spieëlbeeld, naamlik hoe 'n vrou en haar man die vrou se verwante aanspreek of na verwys, kom nie eers hier ter sprake nie.

Die leksikograaf se rol is dié van 'n tussenganger tussen 'n komplekse struktuur aan die een kant en die woordeboekgebruiker aan die ander kant. Vir die doel van hierdie artikel word aanleerders van Sepedi as teikengebruikers geïdentifiseer.

Daar sal eerstens gepoog word om 'n lemmatiseringstrategie vir verwantskapsterme in Sepedi te formuleer uit die aanbod van enkelwoorde, samestellings en konstruksies in Prinsloo en Van Wyk (1992). Tweedens word verwantskapsterme in Prinsloo en Van Wyk (1992) se voorkoms in die Pretoria Sepedi Corpus (PSC) bestudeer en die lemmatisering en bewerking van verwantskapsterme in bestaande woordeboeke vir Sepedi onder die loep geneem. Evaluering van Sepediwoordeboeke word in terme van die lemmaaanbod en die kwaliteit van die bewerking gedoen. Derdens word 'n nuwe leksikografiese konvensie voorgestel vir die lemmatisering van verwantskapsterme in omvattende aanleerderswoordeboeke vir Sepedi.

Die lemmatisering van verwantskapsterme in 'n algemene woordeboek is ' $n$ gegewe en geen woordeboek kan bekostig om nie terme soos oom, broer, suster, oupa of ouma te lemmatiseer en te bewerk nie. Die omvang en kompleksiteit van verwantskapsterminologiestelsels verskil egter van mekaar. So, byvoorbeeld, gee Macmillan English Dictionary (MED) die volgende diagram in figuur 1. 


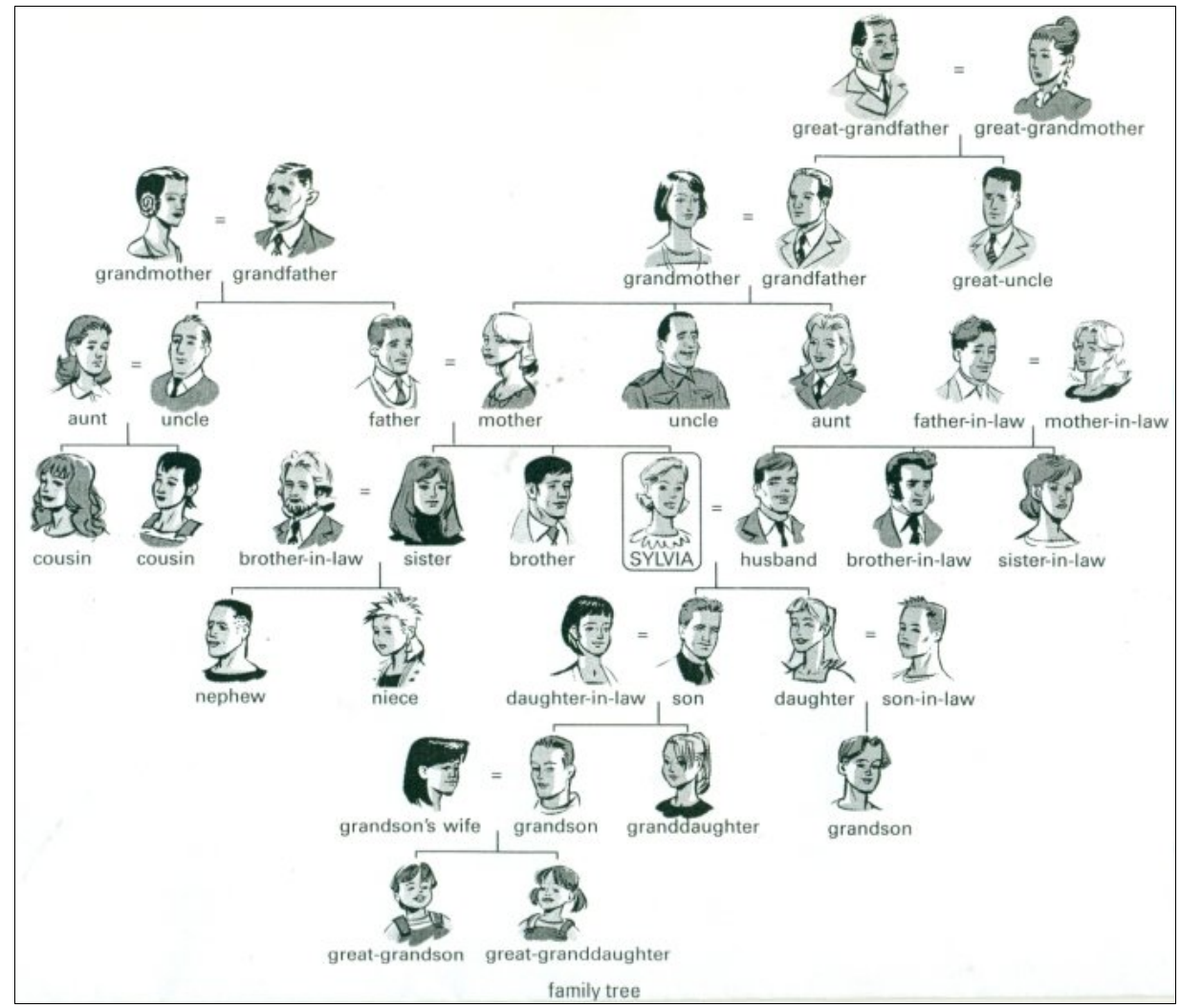

Figuur 1: Familiestamboom in MED

Prinsloo en Bosch (2012) verwys na figuur 1 as 'n struktuur van interpreteerbare kompleksiteit (comprehensible complexity) waarvan die terme met behulp van standaard leksikografiemetodes bewerk kan word terwyl hulle meen dat verdere gebruikersleiding nodig is in die geval van verwantskapsterminologiestelsels vir isiZulu en Sepedi.

\section{Sepedi verwantskapsterminologie as 'n komplekse sisteem}

Teenoor figuur 1 staan die verwantskapstelsel van Sepedi in figuur 2 in skrille kontras en kan laasgenoemde nie bloot leksikografies hanteer word deur met die blote bewerking van verwantskapsterminologie lemmas in die sentrale teks van die woordeboek te volstaan nie. 


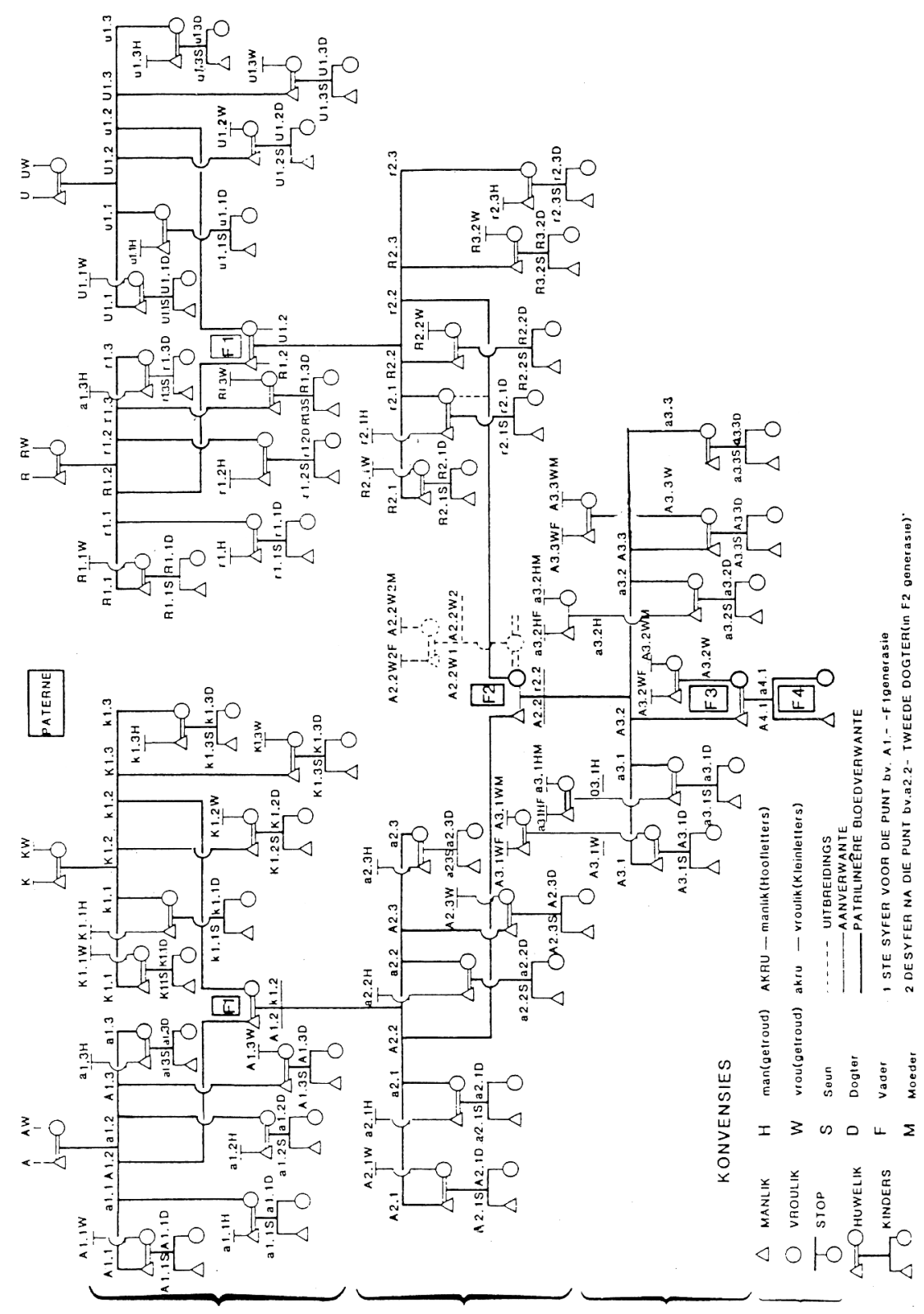

Figuur 2: Paterne diagram vir Sepedi (Prinsloo en van Wyk 1992: 45)

Hierdie figuur is selfs te kompleks vir aanbieding in die agtertekste-afdeling van die woordeboek en ten beste geskik as die verwysingsadres in 'n buiteteks, 
soos byvoorbeeld Prinsloo en Van Wyk (1992). Figuur 2 reflekteer verder slegs die paterne relasies (hoe 'n man A2.2 en sy vrou r2.2 die man se verwante sal aanspreek of na hulle sal verwys).

Figuur 2 bied nietemin die ideale vertrekpunt vir die leksikograaf in die lemmatiseringsproses van verwantskapsterme. In die eerste plek moet hy/sy die komplekse struktuur kan afbreek in terme van die "boustene", byvoorbeeld die verskillende generasies soos 'n man se vader se broers en susters in figuur 3. So, byvoorbeeld, kan die Sepedi leksikograaf die stelsel in figuur 2 afbreek tot 19 boustene soos deur Prinsloo en Van Wyk (1992) gedoen is. Sekere gedeeltes of die samevoeging van gedeeltes kan dan as verteerbare vereenvoudigde skematiese voorstellings met voorbeelde in die agtertekste-afdeling aangebied word.

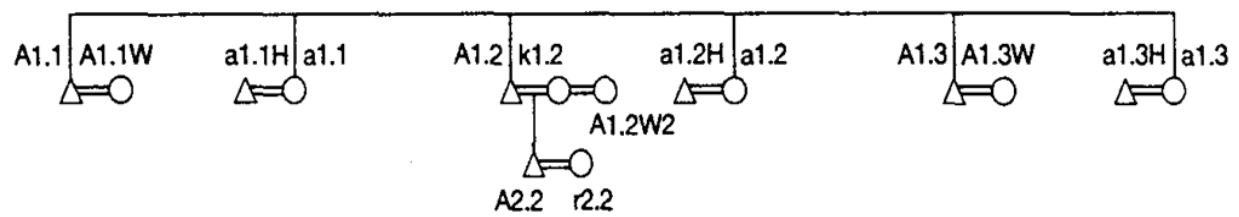

Figuur 3: Verwantskapsterme vir 'n man se vader se broers en susters

\begin{tabular}{|c|c|c|}
\hline \multicolumn{3}{|c|}{ Aanspreekvorme/variante (Verwysingsterme tussen hakies) } \\
\hline F2-Generasie & Ego A2.2 (manlik) & Ego r2.2 (vroulik) \\
\hline Oom & A1.1 Ramogolo (Ramogolo) & \\
\hline Tante & $\begin{array}{l}\text { A1.1W Mmamogolo (Mmamogolo/ } \\
\text { Mogatša ramogolo) }\end{array}$ & $\begin{array}{l}\text { Soos vir ego A2.2 met opsionele } \\
\text { byvoeging van 'wa mogatšaka' } \\
\text { 'van my eggenoot' }\end{array}$ \\
\hline Tante & $\begin{array}{l}\text { a1.1 Rakgadi (Rakgadi/Rakgadi } \\
\text { yo mogolo) }\end{array}$ & \\
\hline Oom & $\begin{array}{l}\text { a1.1H Mogatša' rakgadi/Rakgadi } \\
\text { (Mogatša' rakgadi yo mogolo) }\end{array}$ & \\
\hline Vader & A1.2 Tate (Tate) & Tate/Ratswale (Ratswale) \\
\hline Moeder & $\mathrm{k} 1.2 \mathrm{Mme} / \mathrm{Mma}(\mathrm{Mme} / \mathrm{Mma})$ & $\begin{array}{l}\text { Mme/Mma/Matswale (Mme/ } \\
\text { Mma/Matswale) }\end{array}$ \\
\hline Vader se vrou & $\begin{array}{l}\text { A1.2W2 Mmane/Mmangwane } \\
\text { (Mmane/Mmangwane Mogatša' } \\
\text { tate wa bobedi) }\end{array}$ & $\begin{array}{l}\text { Mmane/Mmangwane (Mmane/ } \\
\text { Mmangwane Mogatša wa ratswale } \\
\text { wa bobedi) }\end{array}$ \\
\hline Oom & A1.3 Rangwane (Rangwane) & \\
\hline Tante & $\begin{array}{l}\text { A1.3W Mmane/Mmangwane } \\
\text { (Mmane/Mmangwane Mogatša } \\
\text { rangwane) }\end{array}$ & $\begin{array}{l}\text { Soos vir ego A2.2 met opsionele } \\
\text { byvoeging van 'wa mogatšaka' } \\
\text { 'van my eggenoot' }\end{array}$ \\
\hline Tante & $\begin{array}{l}\text { a1.2 Rakgadi (Rakgadi (yo } \\
\text { monyane)) }\end{array}$ & \\
\hline
\end{tabular}




\begin{tabular}{|l|l|l|}
\hline Oom & $\begin{array}{l}\text { a1.2H Mogatša' rakgadi/Rakgadi } \\
\text { (Mogatša' rakgadi (yo monyane) }\end{array}$ & \\
\hline Tante & $\begin{array}{l}\text { a1.3 Rakgadi (Rakgadi (yo a } \\
\text { latelago rakgadi yo monyane)) } \\
\text { (yo monyane) }\end{array}$ & $\begin{array}{l}\text { Soos vir ego A2.2 met opsionele } \\
\text { byvoeging van 'wa mogatšaka' } \\
\text { 'van my eggenoot' }\end{array}$ \\
\hline Oom & $\begin{array}{l}\text { a1.3H Mogatša' rakgadi/Rakgadi } \\
\text { (Mogatša' rakgadi (yo a latelago } \\
\text { rakgadi yo monyane) }\end{array}$ & \\
\hline
\end{tabular}

Tabel 1: Verwantskapsterme vir 'n man se vader se broers en susters

(Prinsloo en Van Wyk 1992: 47-48)

In hierdie voorbeeld word die verwantskapstruktuur en verwantskapsterme van 'n man se vader se broers en susters meer gebruikersvriendelik as in figuur 2 aangebied bloot omrede kleiner gedeeltes een vir een aan die orde gestel word. Dit doen nie afbreuk aan die geheelbeeld nie maar bied die ooreenkomste en verskille, veral ten opsigte van hoe die persoon aangespreek word teenoor hoe daar na die persoon verwys moet word in verteerbare eenhede. Die boomdiagram vorm steeds 'n kernelement van die inligtingsaanbod. Die eerste taak in terme van die afbreek van komplekse verwantskapsterminologiestelsels behels dus bestudering van die struktuursamestelling en die identifisering en analise van die boustene, bv. figure 2 en 3.

\section{Lemmatisering}

Die tweede hoofaktiwiteit lê op grammatikale vlak in terme van die analise, groepering en redusering van sintaktiese strukture en is sonder meer afgestem op lemmatisering. Die benadering hier is gerig op die onervare teikengebruiker wat Sepedi wil leer en 'n omvattende woordeboek vir reseptiewe (dekoderende) sowel as produktiewe (enkoderende) doeleindes wil gebruik. Geen grondige kennis van die grammatika van Sepedi word dus voorveronderstel nie. In terme van die Funksieteorie (Tarp 2008), lê die behoefte hier veral op die vlak van die kognitiewe en kommunikatiewe vaardighede.

\subsection{Lemmatisering van enkelwoorde}

Die maklikste gevalle is waar die verwantskapsterm deur 'n onafgeleide enkelwoord in die enkelvoud soos malome 'oom' en mokgotse 'swaer' benoem word. Hierdie verwantskapsterme kan sonder meer gelemmatiseer en leksikografies bewerk word.

Die tweede oorweging raak die lemmatisering van enkelvouds- versus meervoudsvorme van verwantskapsterme. Enkelvouds- en meervoudsvorming word in Sepedi deur prefikse gedoen. Van Wyk (1987) wys daarop dat die 
meervoudsprefiks bo- van klas 2a, byvoorbeeld botate nie sonder meer meervoudigheid aandui nie maar ' $n$ respeksvorm kan wees, of meervoudigheid in die vorm van vader-hulle aandui. Tabel 2 illustreer die sisteem vir die eerste agt naamwoordklasse uit die naamwoordklassesisteem van Sepedi.

\begin{tabular}{|l|l|l|l|l|}
\hline Klas & Prefiks & Voorbeeld & Besitskakel & Besitlike voornaamwoord \\
\hline 1 & mo- & monna 'man' & wa & gagwe \\
\hline 2 & ba- & banna 'mans' & ba & bona \\
\hline $\mathbf{1 a}$ & $\mathbf{\boldsymbol { \sigma }} / \mathbf{N}-$ & tate 'vader' & wa & gagwe \\
\hline $\mathbf{2 b}$ & bo- & botate 'vaders' & ba & bona \\
\hline 3 & mo- & motse 'stat' & wa & wona \\
\hline 4 & me- & metse 'statte' & ya & yona \\
\hline 5 & le- & lesogana 'jongman' & la & lona \\
\hline 6 & ma- & masogana 'jongmans' & a & ona \\
\hline 7 & se- & selepe 'byl' & sa & sona \\
\hline 8 & di- & dilepe 'byle' & tša & tšona \\
\hline
\end{tabular}

Tabel 2: Die eerste agt naamwoordklasse van Sepedi

Enkelvouds- en meervoudsaanduiding deur middel van prefikse is uiteraard problematies deurdat die leksikograaf moet besluit of hy/sy slegs enkelvoude of enkelvoudsvorme sowel as meervoudsvorme wil lemmatiseer. So, byvoorbeeld, moet die leksikograaf besluit of slegs monna en tate, of beide monna en banna, en tate en botate in tabel 2 gelemmatiseer moet word. Laasgenoemde neem uiteraard meer ruimte in die woordeboek in beslag en die lemmas kom in verskillende artikeltrajekte tereg, wat op sy beurt weer kruisverwysings impliseer indien die leksikograaf nie beide die enkelvouds- en meervoudsvorme volledig wil bewerk nie.

Pukuntšu Dictionary (PUKU 1) lemmatiseer beide enkelvouds- en meervoudsvorme. Die gebruiker kan dus monna onder mo- en banna onder barespektiewelik in die alfabetiese gedeeltes $\mathrm{M}$ en B in die woordeboek opsoek. Dieselfde geld vir mokgotse 'swaer, skoonsuster' waar ook die meervoudsvorm bakgotse 'swaers', en beide malome 'oom, ma se broer' en die meervoudsvorm bomalome 'ooms, ma se broers' as afsonderlike artikels aangebied word. Hierteenoor word slegs enkelvoudsvorme in Pukuntšu woordeboek, Noord-Sotho-Afrikaans, Afrikaans-Noord-Sotho (PUKU 2) gelemmatiseer en word daar van die gebruiker verwag om banna onder monna op te soek en botate onder tate. In laasgenoemde geval voorveronderstel die leksikograaf kennis van die naamwoord- 
struktuur van die gebruiker maar bied ook sekere hulpmiddels in die voorwerk aan wat die gebruiker kan help om die enkelvoudsvorme te bepaal.

Die derde aspek vir besinning ten opsigte van die lemmatisering van enkelwoorde behels afgeleide of saamgestelde vorme, veral die hoëfrekwensieafleidings -ago 'van jou', -agwe ' van hom of haar', mma- 'moeder' en mogatša'eggenoot'. Tabel 3 lys byvoorbeeld die 20 vorme waarin malome in die PSC voorkom.

\begin{tabular}{|l|c|l|}
\hline Verwantskapsterm & Voorkomste in die PSC & Vertaling \\
\hline bomalome & $\mathbf{2 0}$ & ooms \\
\hline bomalomeabo & 1 & hulle ooms \\
\hline bomalomeabona & 1 & hulle ooms \\
\hline bomalomeago & $\mathbf{5}$ & jou ooms \\
\hline bomalomeagwe & $\mathbf{9}$ & sy/haar ooms \\
\hline bomalomeatšona & 1 & hulle ooms \\
\hline bommamalome & $\mathbf{1}$ & die moeders van oom/oom \\
& 1 & se moeder-hulle \\
\hline bomogatšamalomeabona & $\mathbf{5}$ & eggenotes van hulle oom \\
\hline gamalome & $\mathbf{1}$ & by oom se plek \\
\hline gamalomeagwe & $\mathbf{8 3}$ & by sy oom se plek \\
\hline malomeago & $\mathbf{2 0 1}$ & jou oom \\
\hline malomeagwe & 3 & sy/haar oom \\
\hline malomeake & 1 & my oom \\
\hline malomealena & 2 & julle oom \\
\hline malomeatšona & $\mathbf{1 0}$ & hulle oom \\
\hline mmamalome & $\mathbf{3}$ & oom se moeder \\
\hline mmamalomeagwe & $\mathbf{9}$ & sy/haar oom se moeder \\
\hline mogatšamalome & & oom se eggenoot \\
\hline mogatšamalomeagwe & sy/haar oom se eggenoot \\
\hline ngwanamalome & oom se kind \\
\hline
\end{tabular}

Tabel 3: Afleidings van malome in die PSC

Die vraag is of hierdie afleidings, byvoorbeeld die paradigma malomeago 'jou oom', malomeagwe 'sy/haar oom', mmamalome 'oom se moeder' en mogatšamalome 'oom se vrou' afsonderlik gelemmatiseer moet word. Vergelyk byvoorbeeld Oxford Bilingual School Dictionary: Northern Sotho and English (ONSD) ten opsigte van malomeago en malomeagwe in figuur 4. 


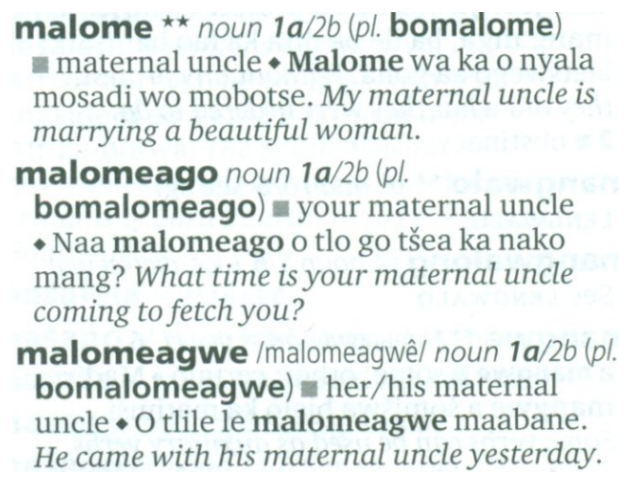

Figuur 4: Malome, malomeago en malomeagwe in ONSD

In wese voeg die laaste twee artikels bloot die betekenis 'van jou' en 'van hom/haar' toe. Vir 'n skoolwoordeboek soos ONSD wat op die basis van gebruiksfrekwensie saamgestel is, is dit aanvaarbaar en gebruikersvriendelik. Die leksikograaf kan egter besluit dat hierdie afleidings nie gelemmatiseer moet word nie omdat hulle genoegsaam deursigtig is en ook nie enige morfofonologiese veranderinge tot gevolg het nie. Die leksikograaf kan dan die gebruiker tegemoetkom deur die afleidings -ago en -agwe binne die artikel van die onafgeleide term te bewerk soos wat dit in PUKU 1 gedoen is waar beide die vorme malomago en malomagwe in die artikel van malome bewerk word. Dat die omvang van afleidings van verwantskapsterme met byvoorbeeld -ago en -agwe baie groot is blyk byvoorbeeld uit die frekwensies van die tien hoogsgebruikte afleidings met-agwe in die PSC:

mmagwe $(1,483)$, 'sy/haar moeder' rragwe (287) 'sy/haar vader' morwagwe (207) 'sy/haar seun' morwediagwe (163) 'sy/haar dogter' mogolwagwe (109), 'sy/haar neef'

\author{
tatagwe $(1,237)$ 'sy/haar vader' \\ mogatšagwe (217) 'sy/haar eggenoot' \\ malomeagwe (201) 'sy/haar oom' \\ morwarragwe (146) 'sy/haar broer' \\ rakgadiagwe (87), 'sy/haar vader se suster'
}

Die vraag is of daar nie 'n alternatiewe lemmatiseringstrategie vir afgeleide vorme gevind kan word nie en hierdie aspek word in paragraaf 3.3 hieronder verder bespreek.

\subsection{Lemmatisering van frases, woordgroepe en grammatikale konstruksies}

Wanneer meer ingewikkelde strukture onder die loep geneem word, is dit wenslik om benewens enkelwoordlemmatisering ook ander opsies te oorweeg. Vergelyk die volgende konstruksies in tabel 5 van Prinsloo en Van Wyk (1992: 50) in tabel 4, as basis vir die eersvolgende analise: 


\begin{tabular}{|l|}
\hline Ego A2.2 (male) \\
\hline A3.1WF Mokgotse (Mokgotse (wa ka) ka morwa yo mogolo) \\
\hline A3.1WM Mogatša wa Mokgotse (Mogatša wa mokgotse (wa ka) ka morwa yo mogolo) \\
\hline a3.1HF Mokgotse (Mokgotse (wa ka) ka morwedi yo mogolo) \\
\hline a3.1HM Mogatša wa mokgotse (Mogatša wa mokgotse (wa ka) ka morwedi yo mogolo) \\
\hline A3.2WF Mokgotse (Mokgotse (wa ka) ka morwa wa bobedi) \\
\hline A3.2WM Mogatša wa mokgotse (Mogatša wa mokgotse (wa ka) ka morwa wa bobedi) \\
\hline a3.2HF Mokgotse (Mokgotse (wa ka) ka morwedi wa bobedi) \\
\hline a3.2HM Mogatša wa mokgotse (Mogatša wa mokgotse (wa ka) ka morwedi wa bobedi) \\
\hline A3.3WF Mokgotse (Mokgotse (wa ka) ka morwa wa phejane) \\
\hline A3.3WM Mogatša wa mokgotse (Mogatša wa mokgotse (wa ka) ka morwa wa phejane) \\
\hline
\end{tabular}

Tabel 4: Man se eie kinders se skoonouers

In tabel 4 tree mokgotse 'swaer' in 'n verskeidenheid konstruksies op waarvan die besitskonstruksie die mees frekwente is byvoorbeeld mogať̌a wa mokgotse (mogať̌a (naamwoord klas 1), wa (besitskakel klas 1) en mokgotse (naamwoord klas 1)) 'eggenoot van mokgotse'. Die leksikograaf het hier te make met die twee sleutelwoorde eggenoot en swaer en kan wel besluit om mogatša wa mokgotse as multiwoord lemma op te neem. Dit sou byvoorbeeld 'n opsie wees in grondslagfase woordeboeke waar daar nie noodwendig aanvaar kan word dat die gebruiker vertroud is met die besitskonstruksie in Sepedi nie.

'n Tweede opsie is om van die standpunt uit te gaan dat die struktuur eggenoot van iemand deursigtig is wat nóg die aanbod as multiwoord lemma nóg enige verdere gebruikersleiding vereis. Dit sou byvoorbeeld gepas wees vir meer gevorderde aanleerders van die taal vir wie beide die besitskonstruksie en waarskynlik ook die betekenis van die hoëfrekwensiewoord mogaťsa (228 voorkomste in die PSC) bekend is.

Die leksikograaf word egter gekonfronteer met 'n verskeidenheid van nog meer komplekse strukture, byvoorbeeld a.3.2HM waar verwysing deur 'n manlike persoon na sy tweede dogter se man se moeder ter sprake is:

Mogatša wa mokgotse (wa ka) ka morwedi wa bobedi

(eggenoot van swaer (van my) met dogter van tweede)

'my tweede dogter se eggenoot se moeder'

Hier het die leksikograaf met drie besitskonstruksies (die eerste twee in tandem) asook met die gebruik van die instrumentalis ( $k a$ 'met') en 'n rangtelwoord (bobedi 'tweede') te make. Die vraag is hoe so 'n komplekse struktuur gelemmatiseer moet word. Die leksikograaf sal met reg huiwer om hierdie voorbeeld as 'n nege-woord lemma op te neem maar besef wel die behoefte aan sterker gebruikersleiding as die blote lemmatisering van enkelwoorde uit die frase. Dit kan ook geargumenteer word dat die struktuur, hoewel baie kompleks, steeds volkome deursigtig is en dat daar gevolglik op enkelwoordlemmas besluit kan word. Dit sou egter beteken dat die onervare gebruiker tot soveel as nege lemmas sou moes opsoek ten einde die betekenis van mogatša wa mokgotse (wa ka) ka morwedi wa bobedi te konstrueer. 
Indien al die terme in tabel 4 in die artikel van mokgotse bewerk sou word, sal dit tot ' $n$ baie lywige artikel vir mokgotse lei. Soortgelyke lemmatisering van die ander komplekse konstruksies in die verwantskapsterminologiesisteem sal nie haalbaar wees in terme van beskikbare spasie in 'n papierwoordeboek nie. Net soos in die geval van afgeleide enkelwoordvorme in 3.1 hierbo is die vraag of daar nie 'n alternatiewe oplossing vir die lemmatisering van frases, woordgroepe en grammatikale konstruksies gevind kan word nie.

\section{3 'n Leksikografiese konvensie vir die lemmatisering van verwantskapsterme}

'n Oplossing vir die herhalende patrone in 3.2 asook vir die talle enkelwoordafleidings wat in 3.1 en in tabel 3 ten opsigte van malome bespreek is, kan gevind word in die samestelling van 'n leksikografiese konvensie vir verwantskapsterminologie. Só 'n konvensie is 'n kompakte substitusiestruktuur vir die redusering van strukture soortgelyk aan die sogenaamde $g a / s a / s e$ konvensie van Prinsloo en Gouws (1996) wat sedertdien in ONSD, Popular Northern Sotho Dictionary (POP) en New Sepedi Dictionary, English-Sepedi (NSD) gebruik word vir werkwoordstamme wat op 'n -e eindig. Die doel is om 'n kragtige konvensie te ontwerp wat vir 'n aantal herhalende partone voorsiening maak. Só 'n konstruksie moet verstaanbaar vir die teikengebruiker wees en in die gebruikersgids van die woordeboek verduidelik word. Vergelyk, byvoorbeeld, die bekendstelling en uitvoerige verduideliking van hierdie konvensie in die voorwerk van NSD, en ook die groot aantal strukture wat deur dié konvensie ondervang word, in figuur 5.

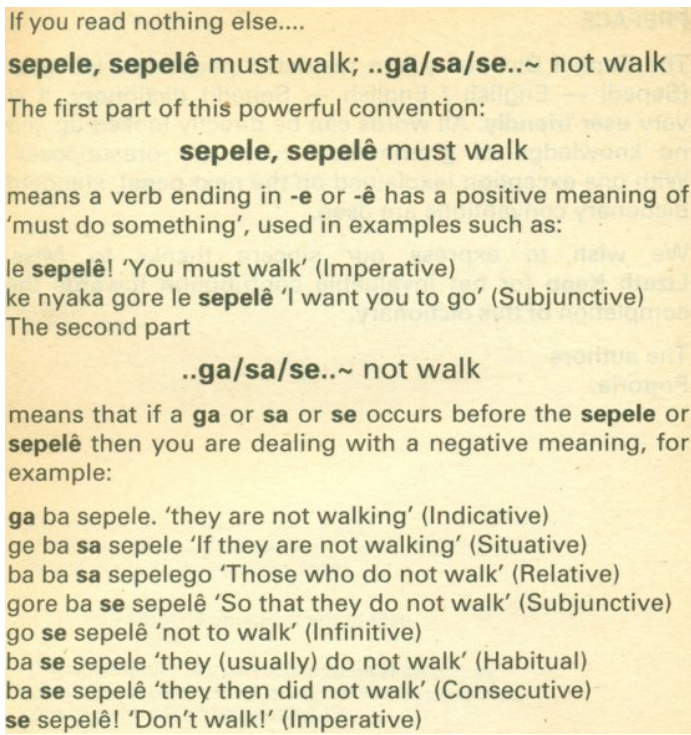

Figuur 5: Gebruikersleiding en aanduiding van die reikwydte van die $g a / s a / s e$ konvensie in NSD 
Vir die lemmatisering van verwantskapsterme word gepoog om 'n enkele konvensie te ontwerp ten einde 'n komplekse stel enkelwoordafleidings, asook ' $n$ komplekse stel frases sinvol te lemmatiseer. Net soos in die geval van die ontwerp van die $g a / s a / s e$ konvensie is dit moontlik om 'n konvensie te ontwerp wat voorsiening maak vir alle elemente van deursigtige herhalingspatrone soos mmago-, mmelega-, -ake, -ago, -agwe en besitskonstruksies soos mogatša (wa) . Die eerste stap is om die elemente te lys wat kandidate is vir opname in die konvensie.

\begin{tabular}{|l|l|}
\hline ga/bo/mma/mogatša (wa)/ngwana (wa)/ & $\begin{array}{l}\text { Elemente wat voor die lemma } \\
\text { optree }\end{array}$ \\
\hline$\sim$ & Die lemma bv. malome \\
\hline $\begin{array}{l}\text { /ago/agwe/abo(na)/ake/atšo(na)/alena/ayo(na)/ } \\
\text { aona/asona/yo mogolo/wa bobedi/phejane/ } \\
\text { mafelelo }\end{array}$ & $\begin{array}{l}\text { Elemente wat na die lemma } \\
\text { optree }\end{array}$ \\
\hline
\end{tabular}

Tabel 5: Kandidaatelemente vir opname in 'n leksikografiese konvensie vir verwantskapsterme

Die struktuur in tabel 5 maak voorsiening vir 'n wye verskeidenheid enkelwoordafleidings en frases. So, byvoorbeeld, ondervang tabel 5 alle afleidings van malome in tabel 3 hierbo asook die grootste gedeelte van strukture in tabel 4 en die volledige paradigma van besitlike voornaamwoorde. Hierdie struktuur is egter te lywig, onprakties en gebruikersonvriendelik vir 'n leksikografiese konvensie. Net soos in die geval van die ontwerp van die $g a / s a / s e$ konvensie (Prinsloo en Gouws: 1996) is dit nodig om die reeks elemente in tabel 5 te verminder op grond van frekwensie tot ' $n$ voorgestelde:

ga/bo/mma/mogatša/ /ake/ago/agwe/abo(na)/ake/atšo(na)/alena

of 'n verder gereduseerde:

bo/mma/mogatša/ /ago/agwe

Die leksikograaf kan besluit watter konvensie die mees doeltreffendste vir die tipe gebruiker en die spesifieke woordeboek sal wees.

\section{Die leksikografiese bewerking van verwantskapsterme in bestaande Sepedi woordeboeke}

Uitvoerige besinning ten opsigte van leemtes in die lemmatisering en bewerking van verwantskapsterminologie is nie moontlik binne die bestek van 'n artikel nie en slegs die mees problematiese aspekte word hier onder die loep geneem. Die eerste leemte raak die lemma-aanbod deurdat daar in die meeste woordeboeke oënskynlik geen seleksiestrategie vir die opname van verwant- 
skapsterme is nie en terme gevolglik maar op sterkte van die intuïsie van die leksikograaf opgeneem is. In tabel 6 word enkelwoord verwantskapsterme uit Prinsloo en Van Wyk (1992) gelys wat in die PSC voorkom, en hulle opname $(\sqrt{ })$, of weglating $(\mathrm{x})$, uit Groot Noord-Sotho-woordeboek, Noord-Sotho-Afrikaans/ Engels (GNSW), Sesotho sa Leboa/English Pukuntšu Dictionary (SLEPD), ONSD, Pukuntšutlhaloši ya Sesotho sa Leboa (PTLH), PUKU 1 en POP. Terme wat in hakies gegee word, is alternatiewe spellings.

\begin{tabular}{|c|c|c|c|c|c|c|c|c|}
\hline Term & Vertaalekwivalent & PSC & GNSW & SLEPD & ONSD & PTLH & PUKU 1 & POP \\
\hline $\begin{array}{l}\text { kgaitšedi/ } \\
\text { (kgaetšedi) }\end{array}$ & broer of suster & 38 & $\sqrt{I} \sqrt{ }$ & $\mathrm{x} / \sqrt{ }$ & $\mathrm{x} / \sqrt{ }$ & $\mathrm{x} / \sqrt{ }$ & $\sqrt{/ \sqrt{ }}$ & $\sqrt{/ \sqrt{ }}$ \\
\hline koko & ouma & 223 & $\sqrt{ }$ & $\sqrt{ }$ & $\sqrt{ }$ & $\sqrt{ }$ & $\sqrt{ }$ & $\sqrt{ }$ \\
\hline malome & oom & 558 & $\sqrt{ }$ & $\sqrt{ }$ & $\sqrt{ }$ & $\sqrt{ }$ & $\sqrt{ }$ & $\sqrt{ }$ \\
\hline matswale & skoonmoeder & 14 & $\sqrt{ }$ & $x$ & $\mathrm{x}$ & $\mathrm{x}$ & $x$ & $\sqrt{ }$ \\
\hline mma & moeder & 1060 & $\sqrt{ }$ & $X$ & $\sqrt{ }$ & $\sqrt{ }$ & $\sqrt{ }$ & $\sqrt{ }$ \\
\hline mmakgolo & ouma & 3 & $x$ & $x$ & $x$ & $x$ & $\sqrt{ }$ & $x$ \\
\hline mmamalome & oom se moeder & 11 & $\mathrm{x}$ & $\mathrm{x}$ & $\mathrm{x}$ & $\mathrm{x}$ & $\mathrm{x}$ & $x$ \\
\hline mmamogolo & $\begin{array}{l}\text { moeder se ouer } \\
\text { suster }\end{array}$ & 57 & $\sqrt{ }$ & $\sqrt{ }$ & $\mathrm{x}$ & $\sqrt{ }$ & $\sqrt{ }$ & $\sqrt{ }$ \\
\hline mmane & $\begin{array}{l}\text { moeder se jonger } \\
\text { suster }\end{array}$ & 61 & $\sqrt{ }$ & $\sqrt{ }$ & $\sqrt{ }$ & $\sqrt{ }$ & $\sqrt{ }$ & $\sqrt{ }$ \\
\hline mmangwane & moeder & 39 & $\sqrt{ }$ & $\sqrt{ }$ & $x$ & $\sqrt{ }$ & $\sqrt{ }$ & $\sqrt{ }$ \\
\hline mmatswale & skoonmoeder & 75 & $\sqrt{ }$ & $\sqrt{ }$ & $\sqrt{ }$ & $\sqrt{ }$ & $x$ & $\sqrt{ }$ \\
\hline mme & moeder & $\begin{array}{l}5524^{*} \\
>100 \\
\end{array}$ & $\sqrt{ }$ & $\sqrt{ }$ & $\sqrt{ }$ & $x$ & $\sqrt{ }$ & $\sqrt{ }$ \\
\hline mogadibo & broer se vrou & 82 & $\sqrt{ }$ & $\sqrt{ }$ & $\sqrt{ }$ & $\sqrt{ }$ & $\sqrt{ }$ & $\sqrt{ }$ \\
\hline $\begin{array}{l}\text { mogadikana/ } \\
\text { (mogadikane) }\end{array}$ & medevrou & 3 & $\mathrm{x} / \sqrt{ }$ & $\sqrt{/ \sqrt{ }}$ & $x / x$ & $\sqrt{/ \sqrt{ }}$ & $x / \sqrt{ }$ & $\mathrm{x} / \sqrt{ }$ \\
\hline mogaditšong & medevrou & 61 & $\sqrt{ }$ & $\sqrt{ }$ & $\mathrm{x}$ & $\sqrt{ }$ & $\sqrt{ }$ & $\sqrt{ }$ \\
\hline mogatšaka & my eggenoot & 188 & $\mathrm{x}$ & $x$ & $\sqrt{ }$ & $x$ & $\mathrm{x}$ & $\sqrt{ }$ \\
\hline mogatšake & my eggenoot & 22 & $\mathrm{x}$ & $x$ & $\mathrm{x}$ & $x$ & $x$ & $x$ \\
\hline mogolle & ouer broer/suster & 90 & $\sqrt{ }$ & $\mathrm{X}$ & $\sqrt{ }$ & $\mathrm{X}$ & $\sqrt{ }$ & $\sqrt{ }$ \\
\hline mogolwake & $\begin{array}{l}\text { my ouer broer/sus- } \\
\text { ter }\end{array}$ & 39 & $x$ & $\mathrm{x}$ & $\mathrm{x}$ & $\mathrm{x}$ & $\mathrm{x}$ & $x$ \\
\hline mokgonyana & skoonseun & 260 & $\sqrt{ }$ & $\sqrt{ }$ & $\sqrt{ }$ & $\sqrt{ }$ & $\sqrt{ }$ & $\sqrt{ }$ \\
\hline mokgotse & swaer/skoonsuster & 189 & $\sqrt{ }$ & $\sqrt{ }$ & $\sqrt{ }$ & $\sqrt{ }$ & $\sqrt{ }$ & $\sqrt{ }$ \\
\hline molamo & swaer & $\begin{array}{c}315^{*} \\
>100\end{array}$ & $\sqrt{ }$ & $\sqrt{ }$ & $\sqrt{ }$ & $\sqrt{ }$ & $\sqrt{ }$ & $\sqrt{ }$ \\
\hline monyanana & $\begin{array}{l}\text { jonger broer of sus- } \\
\text { ter }\end{array}$ & 28 & $\sqrt{ }$ & $x$ & $x$ & $\sqrt{ }$ & $\sqrt{ }$ & $\sqrt{ }$ \\
\hline moratho & $\begin{array}{l}\text { jonger broer of } \\
\text { suster }\end{array}$ & 114 & $\sqrt{ }$ & $\sqrt{ }$ & $\sqrt{ }$ & $\sqrt{ }$ & $\sqrt{ }$ & $\sqrt{ }$ \\
\hline morwa & seun & 3803 & $\sqrt{ }$ & $\sqrt{ }$ & $\sqrt{ }$ & $\sqrt{ }$ & $\sqrt{ }$ & $\sqrt{ }$ \\
\hline morwaka & my seun & 7 & $x$ & $x$ & $x$ & $x$ & $x$ & $\sqrt{ }$ \\
\hline morwake & my seun & 45 & $x$ & $\sqrt{ }$ & $\mathrm{x}$ & $\sqrt{ }$ & $\mathrm{x}$ & $\sqrt{ }$ \\
\hline morwarre & broer & 127 & $\sqrt{ }$ & $\sqrt{ }$ & $\sqrt{ }$ & $\sqrt{ }$ & $\sqrt{ }$ & $\sqrt{ }$ \\
\hline morwedi & dogter & 1000 & $\sqrt{ }$ & $\sqrt{ }$ & $\sqrt{ }$ & $\sqrt{ }$ & $\sqrt{ }$ & $\sqrt{ }$ \\
\hline morwediaka & my dogter & 7 & $x$ & $x$ & $x$ & $x$ & $x$ & $x$ \\
\hline morwediake & my dogter & 34 & $\mathrm{x}$ & $\sqrt{ }$ & $x$ & $\sqrt{ }$ & $x$ & $x$ \\
\hline motlogolo & kleinkind & 177 & $\sqrt{ }$ & $\sqrt{ }$ & $\sqrt{ }$ & $\sqrt{ }$ & $\sqrt{ }$ & $\sqrt{ }$ \\
\hline motswala & neef/niggie & 120 & $\sqrt{ }$ & $\sqrt{ }$ & $\sqrt{ }$ & $\sqrt{ }$ & $\sqrt{ }$ & $\sqrt{ }$ \\
\hline motswalake & my neef/niggie & 14 & $\mathrm{x}$ & $x$ & $\mathrm{x}$ & $\mathrm{x}$ & $\mathrm{x}$ & $\sqrt{ }$ \\
\hline $\begin{array}{l}\text { ngwanangwanake/ } \\
\text { ngwanangwanaka }\end{array}$ & my kleinkind & 5 & $x / x$ & $x / \sqrt{ }$ & $x / x$ & $x / \sqrt{ }$ & $x / x$ & $x / x$ \\
\hline ngwanego & jou familielid & 3 & $\mathrm{x}$ & $x$ & $x$ & $x$ & $x$ & $x$ \\
\hline
\end{tabular}




\begin{tabular}{|l|l|r|r|r|r|r|r|c|}
\hline ngwetši & skoondogter & 637 & $\sqrt{ }$ & $\sqrt{ }$ & $\sqrt{ }$ & $\sqrt{ }$ & $\sqrt{ }$ & $\sqrt{ }$ \\
\hline nnake & $\begin{array}{l}\text { my jonger broer/ } \\
\text { suster }\end{array}$ & 8 & $\sqrt{ }$ & $\sqrt{ }$ & $\mathrm{x}$ & $\sqrt{ }$ & $\sqrt{ }$ & $\mathrm{x}$ \\
\hline Rakgadi & vader se suster & 348 & $\sqrt{ }$ & $\sqrt{ }$ & $\sqrt{ }$ & $\sqrt{ }$ & $\sqrt{ }$ & $\sqrt{ }$ \\
\hline Rakgolo & grootvader & 190 & $\sqrt{ }$ & $\sqrt{ }$ & $\sqrt{ }$ & $\sqrt{ }$ & $\sqrt{ }$ & $\sqrt{ }$ \\
\hline rakgolokhukhu & voorvader & 8 & $\sqrt{ }$ & $\sqrt{ }$ & $\mathrm{x}$ & $\sqrt{ }$ & $\sqrt{ }$ & $\mathrm{x}$ \\
\hline ramogolo & vader se ouer broer & 114 & $\sqrt{ }$ & $\sqrt{ }$ & $\sqrt{ }$ & $\sqrt{ }$ & $\sqrt{ }$ & $\sqrt{ }$ \\
\hline rangwane & $\begin{array}{l}\text { vader se jonger } \\
\text { broer }\end{array}$ & 354 & $\sqrt{ }$ & $\sqrt{ }$ & $\sqrt{ }$ & $\sqrt{ }$ & $\sqrt{ }$ & $\sqrt{ }$ \\
\hline ratswale & skoonvader & 26 & $\sqrt{ }$ & $\sqrt{ }$ & $\mathrm{x}$ & $\sqrt{ }$ & $\sqrt{ }$ & $\sqrt{ }$ \\
\hline rra & vader & 55 & $\mathrm{x}$ & $\sqrt{ }$ & $\mathrm{x}$ & $\mathrm{x}$ & $\sqrt{ }$ & $\sqrt{ }$ \\
\hline Samma & jonger broer of sus- & 40 & $\sqrt{ }$ & $\sqrt{ }$ & $\mathrm{x}$ & $\sqrt{ }$ & $\sqrt{ }$ & $\sqrt{ }$ \\
\hline tate/tata & vader & 1517 & $\sqrt{/ \sqrt{ }}$ & $\mathrm{x} / \sqrt{ }$ & $\sqrt{/ \mathrm{x}}$ & $\sqrt{/ \mathrm{x}}$ & $\sqrt{/ \sqrt{ }}$ & $\sqrt{/ \sqrt{ }}$ \\
\hline tatemogolo & oupa & 9 & $\mathrm{x}$ & $\mathrm{x}$ & $\mathrm{x}$ & $\mathrm{x}$ & $\mathrm{x}$ & $\mathrm{x}$ \\
\hline
\end{tabular}

* geskatte frekwensie van verwantskapsterm in geval van homonieme word aangedui deur ">"

Vetgedrukte hoofletters ' $\mathbf{X}$ ' veronderstel belangrike leemtes ten opsigte van die lemmatisering van verwantskapsterme.

Tabel 6: Frekwensie in die PSC en opname in GNSW, SLEPD, ONSD, PTLH, PUKU 1 en POP van enkelwoord verwantskapsterme in Prinsloo en Van Wyk (1992)

Nie alle weglatings, in vergelyking met die ander woordeboeke moet as leemtes beskou word nie. So, byvoorbeeld, is die weglating van matswale, mmakgolo, ratswale, ens. uit ONSD regverdigbaar in terme van gebruiksfrekwensie wat as kriteria vir opname in dié woordeboek dien. Weglating van mma en tate, uit die SLEPD, met 'n gebruiksfrekwensie van respektiewelik 1,060 en 1,517 in die PSC, kan egter as 'n leemte of fout beskou word. Net so is mogolle opvallend afwesig in SLEPD en PTLH.

Die tweede leemte geld die kwaliteit van bewerking van verwantskapsterme wat wel in die woordeboek opgeneem is. In baie gevalle is die gebruikersleiding wat woordeboeke ten opsigte van verwantskapsterme bied nie duidelik nie of selfs misleidend. Die inligtingsaanbod is gewoon nie genoegsaam kontrasterend, gedetailleerd of diskriminerend nie. So, byvoorbeeld, vind die gebruiker wat die woord malome in PTLH opsoek die betekenis kgaetšedi ya mma 'moeder se broer'.

\section{malome (leina ka botee) (1a/2a) \\ kgaetšedi ya mma: Malome \\ kgaetšedi ya mma ke majadihlogo}

Figuur 6: Malome in PTLH

Die gebruiker wat onseker is oor die presiese betekenis van die ander verwantskapsterm in die betekenisparafrase, kgaetšedi, soek dit vervolgens in dieselfde woordeboek op: 


\section{kgaetšedi /kgaetšêdi/ (leina ka botee) \\ (9/10) ngwana wa batswadi ba ka wa mosetsana goba wa mosadi : Tameng kgaetšedi! Naa go bjang ngwanešo?}

Figuur 7: Kgaetšedi in PTLH

Uit die betekenis "n vroulike kind van my ouers' (ngwana wa batswadi ba ka wa mosetsana goba wa mosadi) kan die onervare gebruiker foutiewelik konkludeer dat malome verwys na "n vroulike kind van my ouers van my ma' in plaas van 'moeder se broer'. SLEPD vaar nie veel beter nie deur bloot malome met uncle te vertaal sonder enige verwysing na moederskant. POP en GNSW doen beter met die vertaling van malome as my maternal uncle 'my oom aan moederskant'. Die GNSW-artikel word in figuur 8 aangegee.

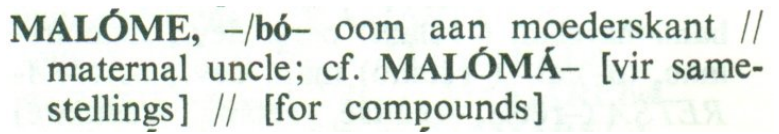

Figuur 8: Malome in GNSW

In POP en SLEPD word die vertaalekwivalente malome, ramogolo, rangwane vir die lemma uncle aangegee. Meer gebruikersleiding soos moeder se broer, vader se ouer/jonger broer is hier noodsaaklik vir beide teksresepsie en teksproduksie.

SLEPD gee ook die vertaalekwivalente vir kgaetšedi as 'my sister, sister' terwyl PUKU 1 die vertaalekwivalente 'jonger suster van 'n broer' en 'jonger broer van 'n suster' aangee. Die gebruiker is dus nie seker of kgaetšedi slegs na 'suster' of na 'suster of broer' kan verwys nie.

Volgens GNSW beteken mogadibo 'broer se vrou' maar is dit 'n term wat slegs deur sy suster gebruik word. SLEPD en ONSD gee egter sonder enige beperking die Engelse vertaling sister in law 'skoonsuster' aan. Hierteenoor gee PUKU 1 naas 'skoonsuster' ook 'skoondogter' as vertaling aan. Dit kan ook die gebruiker verwar.

Die inligtingsaanbod ten opsigte van 'n spesifieke lemma verskil uiteraard in woordeboeke maar die vraag is of die leksikograaf in hierdie gevalle behoorlike voorafstudie van die terme gedoen het.

Die leksikograaf moet ook seker maak dat die inligtingsaanbod by die meervoudsvorm nie verskil van dié by die enkelvoudsvorm nie. So, byvoorbeeld, gee PUKU 1 by mokgotse ook skoonsuster as vertaalekwivalent maar nie in die artikel van die meervoudslemma bakgotse nie. 
Dit is ten slotte opmerklik dat die gebruikersvoorbeelde dikwels nie bydra tot die semantiese kommentaar nie. Vergelyk die volgende voorbeelde uit ONSD:

\begin{tabular}{|c|c|}
\hline $\begin{array}{l}\text { malome }{ }^{\star \star} \text { noun } 1 a / 2 b \text { (pl. bomalome) } \\
\text { maternal uncle } \bullet \text { Malome wa ka o nyala } \\
\text { mosadi wo mobotse. My maternal uncle is } \\
\text { marrying a beautiful woman. }\end{array}$ & $\begin{array}{l}\text { mogolle noun } 1 / 2 \text { (pl. bagolle) alder } \\
\text { sister/brother } \bullet \text { Ga o kwe ge ke re mogolle } \\
\text { o be a diretšwe monyanya. Don't you hear } \\
\text { when I say that a wedding feast was held for } \\
\text { my older sister? }\end{array}$ \\
\hline $\begin{array}{l}\text { mogolo }{ }^{3} \star \text { noun } 1 / 2(\mathrm{pl} \text {. bagolo) } \mathbf{1} \text { alder } \\
\text { sister/brother } \bullet \text { Ge mma wa ka a re soletše } \\
\text { dijo, go thoma mogolo wa ka go kgetha. } \\
\text { When my mother served us food, my older } \\
\text { brother was the first one to choose. }\end{array}$ & $\begin{array}{l}\text { mogadibo /mogadibô/ noun 1/2 (pl. } \\
\text { bagadibo) In sister-in-law } \bullet \text { Mogadibo wa } \\
\text { ka o belege ngwana wa mošemane } \\
\text { maabane. My sister-in-law gave birth to a } \\
\text { baby boy yesterday. }\end{array}$ \\
\hline
\end{tabular}

Figuur 9: Malome, mogolle, mogolo en mogadibo in ONSD

Meer as $50 \%-80 \%$ van die woordeboekspasie vir die artikels van malome, mogolle, mogolo en mogadibo dien nie werklik enige doel ter verheldering van die betekenis nie want in al vier gevalle kan die betrokke lemma bloot met enige ander toepaslike naamwoord vervang word. Dit is wat Rundell (Atkins et al. 1997) lys as een van die tipiese kenmerke van swak voorbeelde naamlik "are natural, typical ... but completely pointless (e.g. Sicilian: a quarrel between two Sicilians)". Selfs die MED se bewerking van uncle stel in hierdie opsig teleur deurdat die gebruiksvoorbeeld the business was owned by my uncle nie tot betekenisverheldering bydra nie:

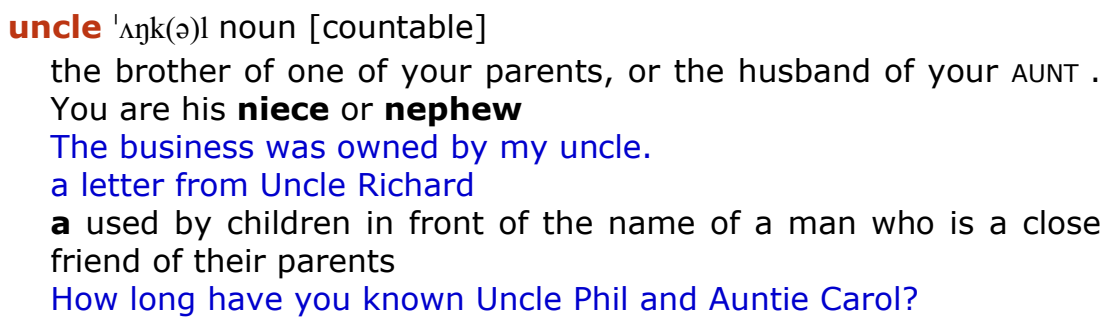

Hier kan uncle netsowel met enige ander naamwoord vervang word. MED is wel voortreflik deurdat Ego in die bewerking van die lemma in ag geneem word dit wil sê in watter verhouding ek tot uncle staan, naamlik sy neef of niggie. Dit dra veel meer by tot die betekenisinligting as die gegewe gebruikersvoorbeeld. Weglating van die gebruikersvoorbeeld in bogenoemde gevalle 
doen weinig afbreuk aan die kwaliteit van die artikel en die leksikograaf kan dit selfs oorweeg om die verhouding waarin die persoon tot die lemma staan as die tipiese gebruiksvoorbeeld aan te bied by verwantskapterme, bv. ek is my oom se niggie en my broer is sy neef.

\section{Samevatting}

Die Sepedi leksikograaf is terdeë bewus van sy/haar rol as tussenganger tussen komplekse grammatikale strukture in die taal aan die een kant en veral die onervare woordeboekgebruiker aan die ander kant. Sekere strukture in die taal soos verwantskapsterminologie, die modale vorme van die werkwoord en kopulatiewe vereis innoverende lemmatiseringstrategieë ten einde die gebruiker in staat te stel om die verlangde inligting in die woordeboek te vind. Die aard en omvang van verwantskapsterme in Sepedi vra ook meer as die blote lemmatisering op lukrake wyse en op sterkte van die intuïsie van die leksikograaf, of die blote gebruik van 'n frekwensieafsnypunt in 'n Sepedi korpus. Wat die lemmatisering van verwantskapsterminologie betref, is aangetoon dat dit problematies is, veral ten opsigte van die lemmatisering van samestellings, oftewel afgeleide enkelwoordvorme en die lemmatisering van frases soos veelvuldige besitskonstruksies. Die leksikograaf moet in die eerste plek alle leksikografiese bewerkingstrategieë soos vertaalekwivalente, parafrases (definisies), gebruiksvoorbeelde en kruisverwysings na buitetekste en eksterne bronne maksimaal benut. Vir die leksikografiese bewerking van komplekse strukture soos verwantskapsterminologie is dit egter nodig om verdere gebruikersleiding te gee, veral ten opsigte van die toegangstruktuur vir afgeleide vorme en verwantskapsterme wat as multiwoord konstruksies voorkom - derhalwe die aanbod van 'n leksikografiese konvensie vir die lemmatisering van verwantskapsterme in omvattende woordeboeke vir onervare gebruikers wat in hierdie artikel voorgestel word.

\section{Literatuurlys}

\section{A. Woordeboeke}

(GNSW) Ziervogel, D. en P.C.M. Mokgokong. 1975. Pukuntšu ye kgolo ya Sesotho sa Leboa, Sesotho sa Leboa-Seburu/Seisimane/Groot Noord-Sotho-woordeboek, Noord-Sotho-Afrikaans/Engels/Comprehensive Northern Sotho Dictionary, Northern Sotho-Afrikaans/English. Pretoria: J.L. van Schaik.

(MED) Rundell, M. (Red.). 2002. Macmillan English Dictionary for Advanced Learners. CD-ROM. Londen: Macmillan Education. Tweede uitgawe 2007 op CD-ROM. Londen: A\&C Black Publishers.

(NSD) Prinsloo, D.J. en B.P. Sathekge. 1996. New Sepedi Dictionary, English-Sepedi (Northern Sotho), Sepedi (Northern Sotho)-English. Pietermaritzburg: Shuter \& Shooter. 
(ONSD) De Schryver, G.-M. et al. (Reds.). 2008. Pukuntšu ya Polelopedi ya Sekolo. Sesotho sa Leboa le Seisimane. E gatišiť̌we ke Oxford/Oxford Bilingual School Dictionary. Northern Sotho and English. Kaapstad: Oxford.

(POP) Kriel, T.J., D.J. Prinsloo en B.P. Sathekge. 1997. Popular Northern Sotho Dictionary, Northern Sotho-English, English-Northern Sotho. Kaapstad: Pharos.

(PTLH) Mojela, M.V. (Red.). 2007. Pukuntšuthaloši ya Sesotho sa Leboa. Pietermaritzburg: Nutrend.

(PUKU 1) Kriel, T.J. 1983. Pukuntšu Dictionary. Pretoria: J.L. van Schaik.

(PUKU 2) Kriel, T.J. en E.B. van Wyk. 1989. Pukuntšu woordeboek, Noord-Sotho-Afrikaans, AfrikaansNoord-Sotho. Pretoria: J.L. van Schaik.

(SLEPD) Mojela, M.V., M.C. Mphahlele, M.P. Mogodi en M.R. Selokela. 2006. Sesotho sa Leboa/ English Pukuntšu Dictionary. Kaapstad: Phumelela.

\section{B. Ander literatuur}

Atkins, B.T. Sue, M. Rundell en E. Weiner. 1997. Salex'97. A Training Course in the Compilation of Monolingual Dictionaries. Ongepubliseerde kursusmateriaal van 'n tutoriaal gehou by die Woordeboekeenheid vir Suid-Afrikaanse Engels, Rhodes Universiteit, Grahamstad, 15-26 September 1997.

Prinsloo, D.J. en Sonja E. Bosch. 2012. Kinship Terminology in English-Zulu/Northern Sotho Dictionaries - A Challenge for the Bantu Lexicographer. Fjeld, Ruth Vatvedt en Julie Matilde Torjusen (Reds.). 2012. Proceedings of the 15th Euralex International Congress, 7-11 August 2012: 296-303. Oslo: Department of Linguistics and Scandinavian Studies, University of Oslo.

Prinsloo, D.J. en R.H. Gouws. 1996. Formulating a New Dictionary Convention for the Lemmatization of Verbs in Northern Sotho. South African Journal of African Languages 16(3): 100-107.

Prinsloo, D.J. en J.J. van Wyk. 1992. Verwantskapsterminologie van die Noord-Sotho. South African Journal of Ethnology 15(2): 43-58.

Tarp, Sven. 2008. Lexicography in the Borderland Between Knowledge and Non-knowledge. General Lexicographical Theory with Particular Focus on Learner's Lexicography. Lexicographica. Series Maior 134. Tübingen: Max Niemeyer.

Van Wyk, E.B. 1987. Proclitic bo of Northern Sotho. South African Journal of African Languages 7(1): $34-42$. 